Ophthalmic Res 1997;29:364

\title{
Subject Index Vol. 29, No. 5, 1997
}

Adeno-associated virus 261

Adenosine 354

Adenovirus 261

Age-related macular degeneration

242,341 Artificial eye 269

Choroidal neovascularization 341 Clinician 252 Cone survival 290

MHC class II 298 Microphotodiode arrays 269 Mouse 261

Pericytes 320 Peripherin/rafc 261 Permeability 354 Proliferative vitreoretinopathy 242 Protein kinase C 354

Diabetic retinopathy 354

Electrophysiology 305

Functional assessment 305

Gene mapping and identification 252

therapy 242

transfer 261 Glia-neuron interactions 326 Graft 290

Growth factors 341,354

Hemodynamics 320 Hereditary eye diseases 252 Herpes simplex virus thymidine

kinase 242 Homeostasis of extracellular

milieu 326

Implant 281

Interferon $\gamma 298$

Intraretinal transplantation 305

Ion channels 326

Ischemic retinopathies 354

Learning 281

Rabbit 298 RCSrat 305 Reactive glia 326 Rejection 298 Retina 261

Retinal degeneration 269, 281, 290

ganglion cell degeneration 305

implant 269

information processing 281

pigment epithelial cells 298

- epithelium 261

vessels 320 Retroviral vector 242

Signal transduction 354 Subretinal implant 269

Transmitter recycling 326 Transplantation 298 Trophic effect 290 Tyrosine kinase 354

Vascular architecture 320 
- $\quad$ endothelial growth factor 354

Vasopermeability factor 354

Viral vector 261

Visual prosthesis 269, 281

KAHGEÍl

E-Mail karger@karger.ch Fax + 41613061234 http://www. karger. ch C)1997S. KargerAG, Basel 